\title{
Supporting students with disabilities and limited English proficiency: STEM educator professional development participation and perceived utility
}

\author{
S. Li ${ }^{1 *}$, J. V. Ernst ${ }^{2}$ and T. O. Williams ${ }^{3}$
}

\begin{abstract}
Background: Professional development offerings assist K-12 educators in addressing new and evolving classroom dynamics, circumstances, and situations. With the emerging demands of an increasingly science, technology, engineering, and mathematics (STEM)-infused society, teachers are challenged to provide high-quality service and equitable educational opportunities to all STEM education students, particularly to those students who traditionally are underrepresented in comparison to their peers in STEM education and/or have aspirations of participation in STEM-related careers. This study investigated K-12 STEM educator participation and perceived utility regarding professional development addressing specific needs of students with identified categorical disabilities and limited English proficiency (LEP).

Results: Collection and analysis methods employed data retrieval and tabulation from the 2011-2012 School and Staffing Survey (SASS) Teacher Questionnaire (TQ). The national restricted access dataset was used to identify targeted teacher populations as well as provide a profile of STEM teacher participation in practice-oriented professional development activities regarding the two specified student groups. The results were categorically summarized and compared across science, technology, and mathematics (STM) disciplines and also between STM educators, non-STM educators, and educators in general.

Conclusions: The results indicated that STM teachers tended to engage in fewer professional development opportunities and dedicated fewer hours in the professional development regarding students with categorical disabilities and LEP than the remainder of the teaching population. Overall, STM teachers' perceived utility of the provided professional development experience was lower than that of the remainder of the teaching population.

Keywords: STEM education, School and Staffing Survey Teacher Questionnaire, Students with disabilities, Limited English proficiency, Teacher professional development
\end{abstract}

\section{Background}

Science, technology, engineering, and mathematics (STEM) educators in the US are working with increasingly inclusive student populations, including students with categorical disabilities and limited English proficiency (LEP). A list of 13 categorical disabilities have been identified for individuals ages 3 through 21 years

\footnotetext{
* Correspondence: Isz@vt.edu

${ }^{1}$ Integrative STEM Education, School of Education, Virginia Tech, 366 Smyth Hall, Blacksburg, VA 24061, USA

Full list of author information is available at the end of the article
}

old by the Individuals with Disabilities Education Act (2012), including (1) autism, (2) deaf-blindness, (3) deafness, (4) emotional disturbance, (5) hearing impairment, (6) intellectual disability, (7) multiple disabilities, (8) orthopedic impairment, (9) other health impairment, (10) specific learning disability, (11) speech or language impairment, (12) traumatic brain injury, and (13) visual impairment (including blindness). The federal term "LEP" represents a group of students primarily speaking languages other than English. These students are also referred to as "English 
language learners (ELLs)" and "emergent bilingual (EB)" by educators (García 2009).

K-12 STEM educators are expected to inform STEM learning and encourage pursuit of future STEM education and careers. However, Newman et al. (2011) identified that less than $9 \%$ of undergraduate university students with disabilities reported majors in engineering and only $6 \%$ reported majors in either science or computer-related areas. Resultant of global discovery and development, the effectiveness of STEM education is important for national wealth and welfare in the future (President's Council of Advisors on Science and Technology (US) 2010). STEM education helps prepare citizens to make informed decisions and adapt to life and work in an increasingly technological world. However, students with disabilities and LEP often have systemic barriers to engagement (Newman et al. 2011) and are consequently less likely to pursue STEM majors or careers. Although there is a growing job market in STEM-related areas, for undetermined reasons, these groups of students are less likely to participate. Posteducational career prospects for these students can be enhanced through accessible and meaningful STEM education opportunities. Student STEM educational experiences in secondary education influence pursuit of STEM-related careers (Yu et al. 2012). Equitable access to these experiences would prospectively encourage these traditionally underrepresented students (students with disabilities and students with LEP) to choose STEM majors and, subsequently, future careers.

It is imperative that students with LEP receive quality STEM educational experiences where practitioners are not only equipped to address specific educational needs but position themselves within an advocacy role (Zehr 2010). Similarly, STEM practitioners are expected to individualize and differentiate instruction to build meaningful learning experiences for students with disabilities (Sotomayer 2013). Genuine understanding and informed advocacy are also central features in ensuring access for learners while enhancing preparations to maximize learner outcome (Goeke and Ciotoli 2014). Capacity building opportunities for teachers traditionally come in the form of professional development offerings. Professional development opportunities may not provide prescribed context for curricula but help teachers transfer knowledge into instructional practice (McCutchen et al. 2002). "Enhancing the quality ... of K-12 STEM education is inextricably linked to the continued professional development of K-12 teachers" (Nadelson et al. 2012, p. 69). Podhajski et al. (2009) indicate that effective professional development has a positive influence on students' scientific-associated abilities. Nimisha et al. (2012) found that professional development engaging teachers with useful pedagogy in mathematics solidified teacher's familiarity with such strategies. Further, quality professional development improves teacher skills of identifying and addressing student misconceptions, as well as improving teacher pedagogical content knowledge.

Epistemological and pedagogical teacher conceptions, paired with professional practical knowledge, are core factors of teacher learning experiences that enable the transformation of research into practice (Rivero et al. 2011). With the vast array of content-based professional opportunities, a low level of practice-based engagement in professional development for STEM educators persists. Teacher classroom practices, reflecting pedagogical content knowledge and knowledge of learners, are very important. Even short-term professional development can significantly impact educators' attitudes, preparedness, and responsiveness to students with disabilities (Rule et al. 2011). Exemplary teacher learning and professional development models have been identified to promote notable successes with students with disabilities or LEP (Burgstahler and Doe 2004; Lee et al. 2004). However, many professional development opportunities operate without identifiable evidence-based frameworks (Schumm and Vaughn 1995; Avalos 2011).

As classrooms become more inclusive, many teachers will need to provide additional accommodations for students with disabilities and LEP. Professional development can influence teacher's perspectives and practices in STEM teaching and narrow the achievement gaps between the two concerned student groups and the remaining student population (Lee et al. 2008; Hart and Lee 2003; Gándara 2006). On the other hand, teachers' perceptions of professional development could mediate teaching practice and inform on-going and future professional development offerings (Lee et al. 2008). In addition, the focus of the STEM educational shift for students with disabilities and LEP is in a gradual transition from an exclusive subject content knowledge focus to the development of associated reasoning and problem-solving skills (Crippen and Archambault 2012), providing a direction and charge for a new classroom context. Provided the emerging trajectory of STEM education professional development based on new learner needs and societal demands, further targeted offerings are necessary. However, levels and perceptions of meaningful STEM educator participation in professional development specific to students with disabilities and LEP are currently unclear from a national perspective. To explore the professional development status issue, an investigation was designed, coordinated, and implemented.

\section{Research questions}

This investigation was guided by five research questions associated with STEM educator participation in professional development specifically crafted to address needs of students with disabilities and LEP. The guiding questions are as follows: 
Table 1 Teacher demographics by subject

\begin{tabular}{llllll}
\hline & & Mathematics & Science & Technology & All others \\
\hline Total number & & 281,990 & 226,700 & 50,610 & $2,825,880$ \\
Gender $(n(\%))$ & Male & $98,050(34.8)$ & $86,520(38.2)$ & $38,150(75.4)$ & $578,910(20.5)$ \\
& Female & $183,940(65.2)$ & $140,170(61.8)$ & $12,460(24.6)$ & $2,246,980(79.5)$ \\
Race $(n(\%))$ & White & $246,310(87.3)$ & $201,770(89.0)$ & $46,520(91.9)$ & $2,552,240(90.3)$ \\
& Black & $23,330(8.3)$ & $15,750(6.9)$ & $2410(4.8)$ & $2,155,670(7.6)$ \\
& Asian & $11,920(4.2)$ & $8780(3.9)$ & $1140(2.3)$ & $53,230(1.9)$ \\
& Pacific Islander & $850(0.3)$ & $1260(0.6)$ & $250(0.5)$ & $8990(0.3)$ \\
& American Indian & $3260(1.2)$ & $3280(1.4)$ & $1370(2.7)$ & $40,730(1.4)$ \\
& Hispanic & $18,270(6.5)$ & $14,420(6.4)$ & $3560(7.0)$ & $227,870(8.1)$ \\
\hline
\end{tabular}

Weighed sample values are rounded to the nearest 10 per NCES protocol

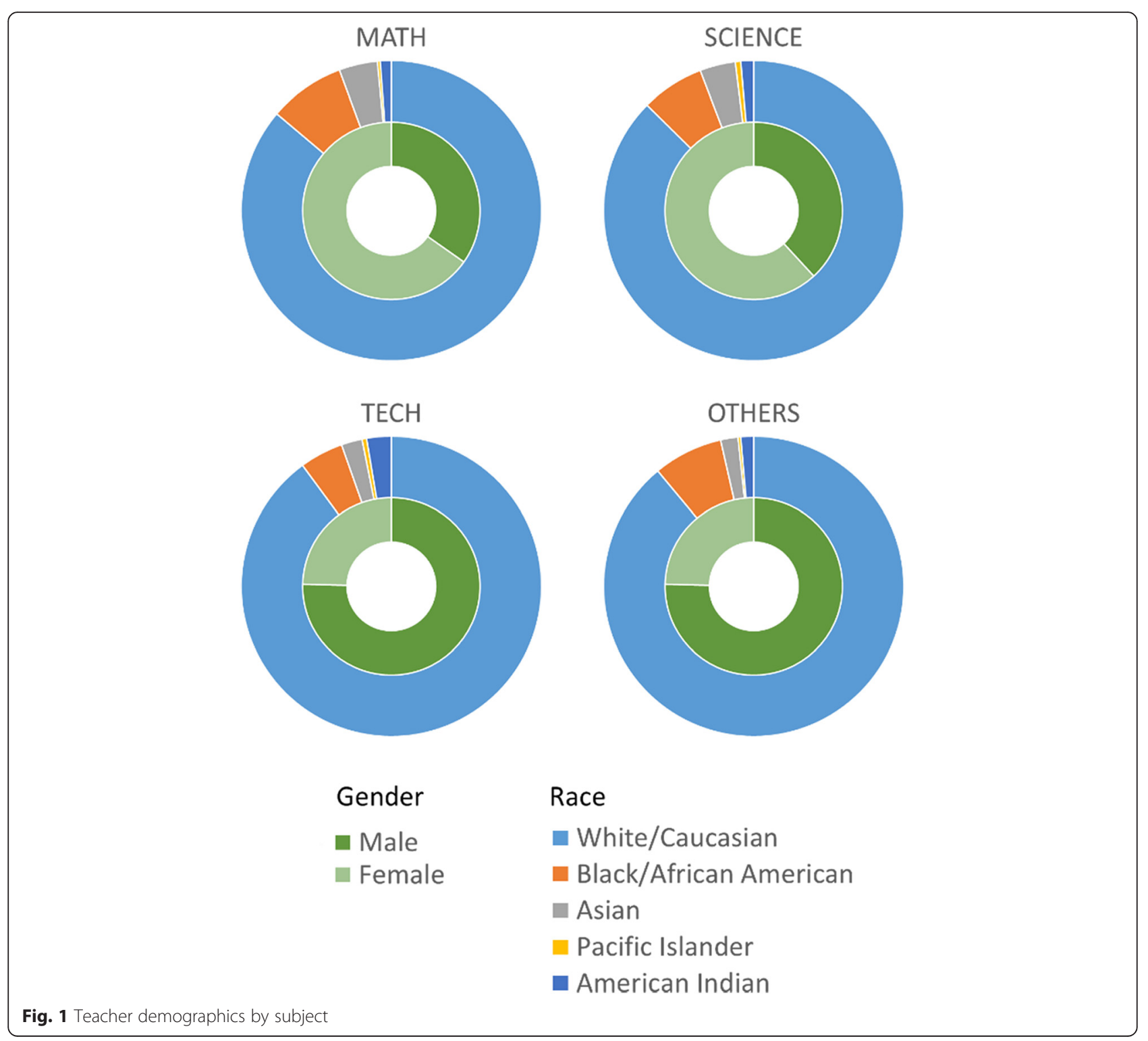


Table 2 Teacher service load by subject

\begin{tabular}{|c|c|c|c|c|c|}
\hline & & Mathematics & Science & Technology & All others \\
\hline \multirow[t]{5}{*}{ Categorical disabilities } & Mean & 9.84 & 13.41 & 18.87 & 11.25 \\
\hline & Std. D. & 10.566 & 14.261 & 25.123 & 17.425 \\
\hline & Median & 7 & 10 & 12 & 5 \\
\hline & Range & 100 & 126 & 231 & 483 \\
\hline & Maximum & 100 & 126 & 231 & 483 \\
\hline \multirow[t]{5}{*}{ LEP } & Mean & 5.98 & 7.1 & 7.6 & 7.28 \\
\hline & Std. D. & 12.899 & 15.892 & 20.236 & 25.231 \\
\hline & Median & 1 & 1 & 1 & 1 \\
\hline & Range & 170 & 185 & 200 & 700 \\
\hline & Maximum & 170 & 185 & 200 & 700 \\
\hline
\end{tabular}

(1) What level of participation in professional development opportunities, centered on educating students with disabilities, do K-12 STEM educators demonstrate?

(2) What level of participation in professional development opportunities, centered on educating students with limited-English proficiency, do $\mathrm{K}-12$ STEM educators demonstrate?

(3)Do STEM educators find professional development participation (students with disabilities and LEP) useful?

(4)Does degree of professional development participation (students with disabilities and LEP) vary based on STEM education discipline?

(5)Does degree of professional development participation (students with disabilities and LEP) vary between STEM educators and all other classifications of educators?

These questions are explored through variable isolation of the Schools and Staffing Survey (SASS) where frequency and summary analyses were conducted. Questions were investigated through summation of data and presented in frequency-based and proportional formats.

\section{Instrumentation}

This study employed SASS, a system of related questionnaires, as the instrument. Tourkin et al. (2010, p. 8-9) concisely identified the SASS instrumentation purpose and procedure:

The SASS is conducted by the National Center for Education Statistics (NCES) on behalf of the US Department of Education in order to collect extensive data on American public and private elementary and secondary schools. The SASS provides data on the characteristics and qualifications of teachers and principals, teacher hiring practices, professional development, class size, and other conditions in schools across the nation. SASS is a large-scale sample survey of K-12 school districts, schools, teachers, library media centers, and administrators in the USA. The SASS was designed to produce national, regional, and state estimates for public elementary and secondary

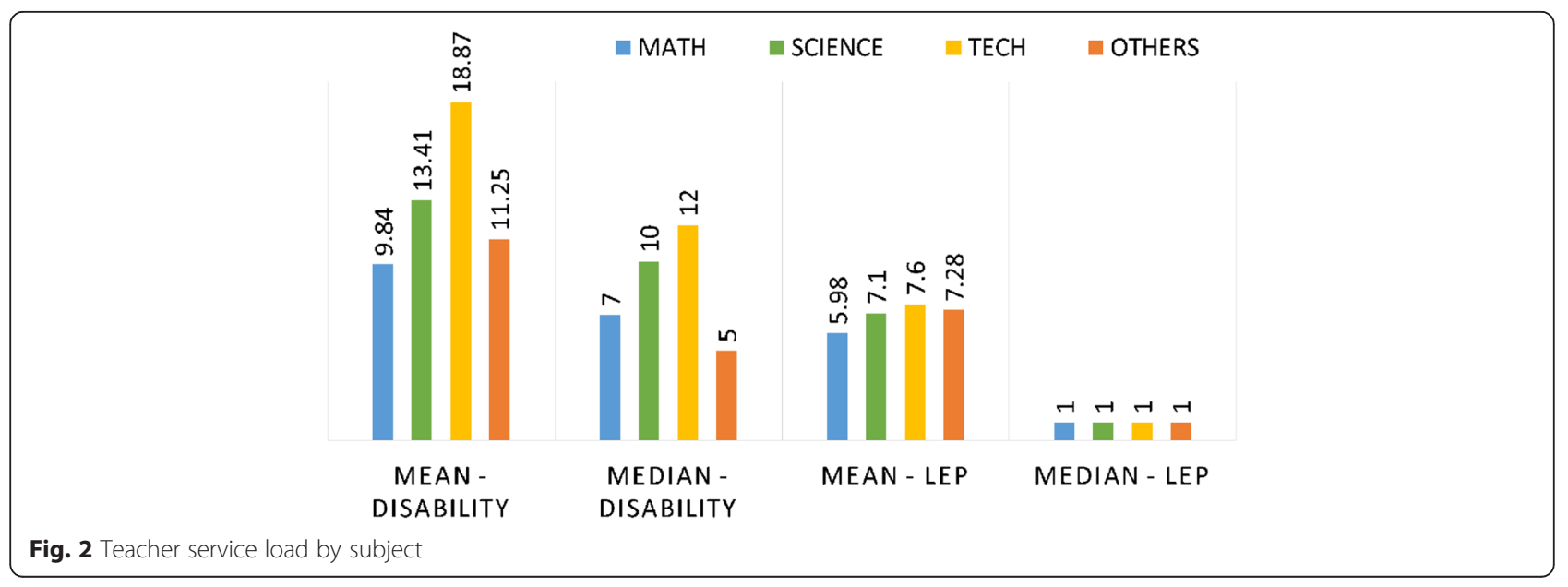


Table 3 Participation in professional development regarding students with categorical disabilities (question 48a)

\begin{tabular}{llll}
\hline Area & Yes $n(\%)$ & No $n(\%)$ & Total \\
\hline Mathematics & $85,020(30.15)$ & $196,970(69.85)$ & 281,990 \\
Science & $68,630(30.27)$ & $158,070(69.73)$ & 226,700 \\
Technology & $17,070(33.73)$ & $33,540(66.27)$ & 50,610 \\
Total STM & $170,710(30.52)$ & $388,580(69.48)$ & 559,290 \\
All others & $1,095,950(38.78)$ & $1,729,930(61.22)$ & $2,825,880$ \\
Total & $1,266,660(37.42)$ & $2,118,510(62.58)$ & $3,385,170$ \\
\hline
\end{tabular}

Weighed sample values are rounded to the nearest 10 per NCES protocol

schools and related components (e.g., schools, teachers, principals, school districts, and school library media centers); national estimates for BIE-funded and public charter schools and related components (e.g., schools, teachers, principals, and school library media centers); and national, regional, and affiliation strata estimates for the private school sector (e.g., schools, teachers, and principals). Therefore, the SASS is an excellent resource for analysis and reporting on elementary and secondary educational issues.

The sampling method of SASS permits a population analysis on a representative sample in the United States, as described on the SASS website:

The SASS uses a stratified probability sample design to ensure that the samples of schools, principals, teachers, districts, and school library media centers contain sufficient numbers for reliable estimates. Public and private schools are oversampled into groups based on certain characteristics. After schools are stratified and sampled, teachers within the schools are also stratified and sampled based on their characteristics (NCES n.d., "Sample selection").

The SASS consisted of five sets of questionnaires: School District Questionnaires, Principal Questionnaires, School Questionnaires, Teacher Questionnaires, and School Library Media Center Questionnaires. The Teacher Questionnaires include the Teacher Questionnaire (SASS TQ) for public school teachers and Private School Teacher Questionnaire. This study employed data retrieved from
2011-2012 SASS TQ to answer research questions. SASS TQ obtained information about teachers, consisting of the following sections: (1) general information, (2) class organization, (3) education and training, (4) certification, (5) professional development, (6) working conditions, (7) school climate and teacher attitudes, (8) general employment and background information, and (9) contact information.

This study examines practice-oriented professional development, specifically referring to professional development regarding students with categorical disabilities and LEP, in the 2011-2012 school year. Question 48a, "In the past 12 months, have you participated in any professional development on how to teach students with disabilities?" (yes or no), question 48b, "In the past 12 months, how many hours did you spend on these activities?", and question 48c, "Overall, how useful were these activities to you?" were adopted to describe the status of teacher professional development regarding students with categorical disabilities.

Question 49a, "In the past 12 months, have you participated in any professional development on how to teach Limited English Proficient students or English-language learners (ELLs)?" (yes or no), question 49b, "In the past 12 months, how many hours did you spend on these activities?", and question 49c, "Overall, how useful were these activities to you?" were adopted to describe the status of teacher professional development regarding students with LEP.

The level of participation in practice-oriented professional development was measured by questions $48 \mathrm{~b}$ and $49 \mathrm{~b}$, regarding teaching students with disabilities and LEP, respectively, on a four-level ordinal scale from "8 hours or less," "9-16 hours," "17-32 hours," to "33 hours or more." Teachers' perception of these professional development experiences was measured by questions $48 \mathrm{c}$ and $49 \mathrm{c}$ on a four-level ordinal scale including "not useful," "somewhat useful," "useful," and "very useful."

\section{Participant description}

The target population for this study was $\mathrm{K}-12$ science, mathematics, and technology teachers in the public school systems of the USA. The groups were defined by

Table 4 Time dedicated in professional development regarding students with categorical disabilities (question 48b)

\begin{tabular}{|c|c|c|c|c|c|}
\hline Area & $\leq 8 \mathrm{~h} n(\%)$ & 9-16 h n (\%) & 17-32 h n (\%) & $\geq 33 \mathrm{~h} n(\%)$ & Total \\
\hline Mathematics & $65,290(76.80)$ & $13,250(15.58)$ & $3980(4.69)$ & $2500(2.93)$ & 85,020 \\
\hline Science & $50,720(73.90)$ & $11,580(16.88)$ & $4430(6.45)$ & $1900(2.77)$ & 68,630 \\
\hline Technology & $12,600(73.82)$ & $2140(12.53)$ & $780(4.59)$ & $1550(9.06)$ & 17,070 \\
\hline Total STM & $128,610(75.34)$ & $26,970(15.80)$ & $9190(5.39)$ & $5940(3.48)$ & 170,710 \\
\hline All others & $719,640(65.66)$ & $195,820(17.87)$ & $103,030(9.40)$ & $77,460(7.07)$ & $1,095,950$ \\
\hline Total & $848,250(66.97)$ & $222,780(17.59)$ & $112,230(8.86)$ & $83,400(6.58)$ & $1,266,660$ \\
\hline
\end{tabular}

Weighed sample values are rounded to the nearest 10 per NCES protocol 
the responses to SASS TQ question 16, "This school year what is you MAIN teaching assignment at THIS school?" Teachers who responded with codes 211, 212, 213,217 , or 218 (biology or life sciences, chemistry, earth sciences, physics, and other natural sciences) were identified as science teachers. Teachers who responded with codes 191, 192, 193, 194, 195, 196, 198, 199, 200, or 201 (algebra I, algebra II, algebra III, basic and general mathematics, business and applied math, calculus and pre-calculus, geometry, pre-algebra, statistics and probability, and trigonometry) were identified as mathematics teachers. Those who were identified as technology teachers responded with codes 246, 249, 250, or 255 (construction technology, manufacturing technology, communication technology, and general technology education). Demographic information regarding the race and gender of the participants was also tabulated by subject in Table 1 and visualized in Fig. 1.

The service load of secondary educators pertaining to education of students having a categorical disability or LEP for the 2011-2012 school year was gauged by the SASS TQ datasets. The teacher service load, which indicated the number of students taught during the school year, was described in Table 2 and Fig. 2 by subject.

\section{Methods}

This study conducted a secondary analysis of the SASS TQ dataset administered by the NCES. Initial access to this dataset was authorized by the NCES to Virginia Tech. A member of the research team was provided designated single-site user admittance to this dataset. As per the restricted access agreement, specific protocol and reporting information was submitted. After review, the NCES authorized approval and release of the frequency and summary analyses.

For the 2011-2012 SASS TQ, there were 3,385,170 instances within the weighted results. The NCES and IES require that all weighted $n$ 's be rounded to the nearest 10 for SASS to assure participant anonymity. Therefore, data in the tables and narrative may not add to the total $N$ reported due to rounding requirements.

The five research questions were explored in this study in terms of teacher professional development participation concerning students with disabilities and LEP. For the purpose of analyses, science, technology, and mathematics (STM) educators and non-STM educators were categorically summarized and compared. The results of STM educators were also analyzed across these three disciplines. The primary variables of interest in this study were the time dedicated by teachers and their perceived utility of the practice-oriented professional development. Following methodological considerations from the study of Ernst et al. (2014, p. 4), "the number of categorized students served was determined by responses

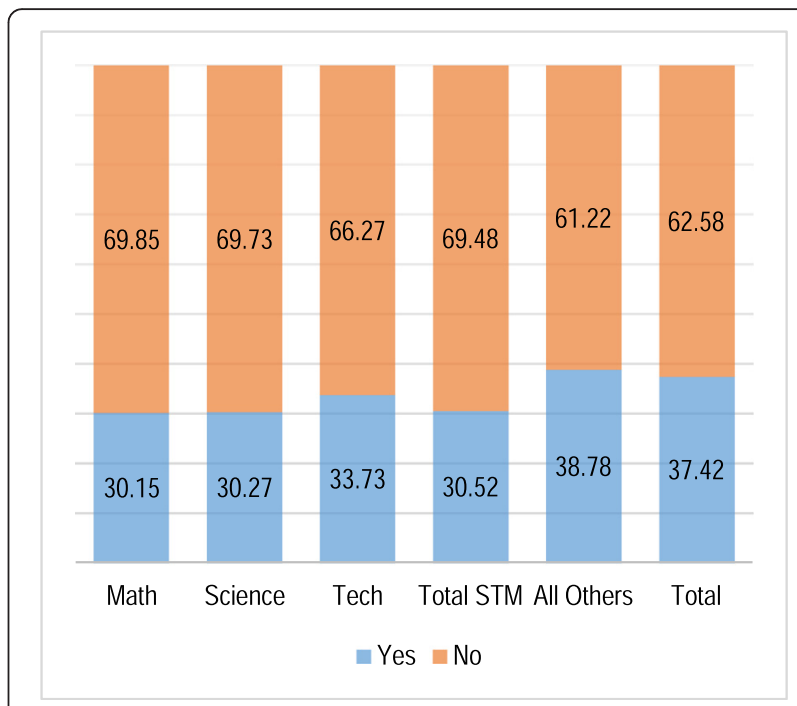

Fig. 3 Participation in professional development regarding students with categorical disabilities (question 48a)

from teachers who reported teaching students with recognized disabilities requiring an individualized education plan. The number of students identified as LEP was determined by responses from teachers who reported teaching students who did not speak English as their primary language and who had a limited ability to read, speak, write, or understand English." Data from the 2011-2012 SASS TQ were extracted and analyzed using descriptive statistics.

\section{Results and discussion}

The number of valid cases for this study was 3,385,170. Self-reported demographic information and teacher service load are summarized in Tables 1 and 2 . Information

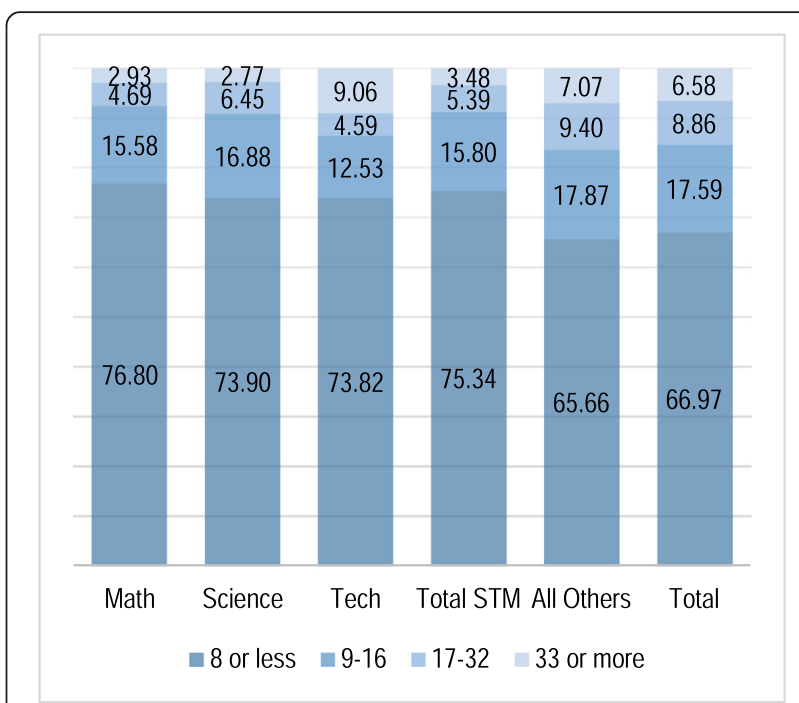

Fig. 4 Time dedicated in professional development regarding students with categorical disabilities (question 48b) 
Table 5 Perceived utility of professional development regarding students with categorical disabilities (question 48c)

\begin{tabular}{llllll}
\hline Area & Not useful $n(\%)$ & Somewhat useful $n(\%)$ & Useful $n(\%)$ & Very useful $n(\%)$ & Total \\
\hline Mathematics & $5370(6.31)$ & $31,690(37.28)$ & $32,540(38.28)$ & $15,420(18.13)$ & 85,020 \\
Science & $5050(7.36)$ & $27,280(39.75)$ & $26,420(38.50)$ & $9870(14.39)$ & $3480(20.36)$ \\
Technology & $940(5.50)$ & $4960(29.03)$ & $7700(45.11)$ & 68,630 \\
Total STM & $11,360(6.65)$ & $63,930(37.45)$ & $66,660(39.05)$ & $28,760(16.85)$ & 17,070 \\
All others & $38,190(3.48)$ & $297,880(27.18)$ & $504,560(46.04)$ & $255,330(23.30)$ & 170,710 \\
Total & $49,540(3.91)$ & $361,810(28.56)$ & $571,220(45.10)$ & $284,090(22.43)$ & $1,095,950$ \\
\hline
\end{tabular}

Weighed sample values are rounded to the nearest 10 per NCES protocol

concerning participation level in professional development centered on educating students with disabilities are summarized in Tables 3 and 4 and presented visually in Figs. 3 and 4. Descriptive analysis showed that STM teachers, especially science and technology teachers, had higher chance to serve students with disabilities based on sample means and medians. However, of all the defined STM teachers, only $30.52 \%$ participated in practice-oriented professional development regarding students with disabilities, which was much lower when compared to $38.78 \%$ of non-STM teachers. Among the teachers who participated, technology teachers had highest service load regarding students with disabilities. Concurrently, they reported a highest percentage in terms of time dedicated in professional development for 33 or more hours associated with students with disabilities. This percentage was about three times that of science and mathematics teachers and higher than that of non-STM teachers. Table 5 and Fig. 5 show teachers' perception of such professional development by subject. There were 20.36 and $45.11 \%$ technology teachers reporting that such professional development was very useful or useful to them; in contrast, only 14.39 and $38.50 \%$ of science teachers reported that this type of

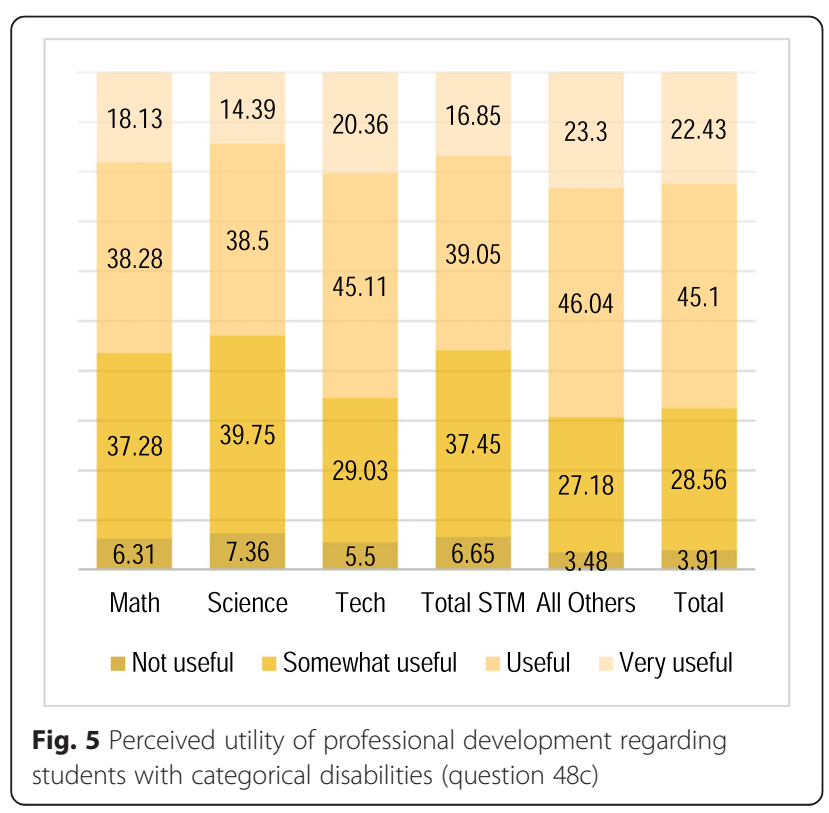

professional development was very useful or useful. Although science teachers also reported relatively high service load as technology teachers did, their time dedicated in and perceived utility of these professional development activities were even lower than non-STM teachers.

According to the results about participation level in professional development centered on educating LEP students shown in Tables 6 and 7, less than $20 \%$ of the technology teachers reported that they participated in professional development on how to teach LEP students, which is the lowest among STM and non-STM teachers, although technology teachers reported highest mean service load on students with LEP. Compared to non-STM teachers, more STM teachers dedicated 8 hours or less in such professional development, and a lower percentage of STM teachers reported 9-16 hours, 17-32 hours, and 33 hours or more. Table 8 shows the teachers' perception of such professional development by subject. About $64 \%$ of the non-STM teachers reported that the professional development experience toward education LEP students was useful or very useful, while only half of the STM teachers were classified in the same categories. Technology teachers had the highest proportion in reporting the professional development regarding LEP students was very useful, followed by non-STM teachers. Mathematics teachers had the least proportion to confirm the utility of such professional development and the most proportion in considering it not useful. This pattern was in accordance with the teacher-reported LEP service load by subject. Figs. 6,7 , and 8 provide graphic representation of the results associated with LEP students.

Table 6 Participation in professional development regarding students with LEP (question 49a)

\begin{tabular}{llll}
\hline Area & Yes $n(\%)$ & No $n(\%)$ & Total \\
\hline Mathematics & $69,970(24.81)$ & $212,020(75.19)$ & 281,990 \\
Science & $53,010(23.38)$ & $173,690(76.62)$ & 226,700 \\
Technology & $9600(18.97)$ & $41,010(81.03)$ & 50,610 \\
Total STM & $132,570(23.70)$ & $426,720(76.30)$ & 559,290 \\
All others & $773,350(27.37)$ & $2,052,530(72.63)$ & $2,825,880$ \\
Total & $905,920(26.76)$ & $2,479,250(73.24)$ & $3,385,170$ \\
\hline
\end{tabular}

Weighed sample values are rounded to the nearest 10 per NCES protocol 
Table 7 Time dedicated in professional development regarding students with LEP (question 49b)

\begin{tabular}{|c|c|c|c|c|c|}
\hline Area & $\leq 8 \mathrm{~h} n(\%)$ & 9-16 h $n(\%)$ & 17-32 h n (\%) & $\geq 33 \mathrm{~h} n(\%)$ & Total \\
\hline Mathematics & $51,580(73.72)$ & $11,080(15.83)$ & $3640(5.20)$ & $3680(5.25)$ & 69,970 \\
\hline Science & $38,210(72.08)$ & $8760(16.53)$ & 3090 (5.83) & $2950(5.57)$ & 53,010 \\
\hline Technology & $6560(68.30)$ & $1410(14.70)$ & $1190(12.43)$ & $440(4.57)$ & 9600 \\
\hline Total STM & $96,340(72.67)$ & $21,250(16.03)$ & 7920 (5.97) & 7070 (5.33) & 132,570 \\
\hline All others & $494,260(63.91)$ & $141,320(18.27)$ & $82,070(10.61)$ & $55,710(7.20)$ & 773,350 \\
\hline Total & $590,600(65.19)$ & $162,570(17.94)$ & $89,980(9.93)$ & $62,770(6.93)$ & 905,920 \\
\hline
\end{tabular}

Weighed sample values are rounded to the nearest 10 per NCES protocol

\section{Conclusions}

Growing job opportunities are offered in STEM fields (Richards and Terkanian 2013) to maintain pace with our STEM-infused societal demands. Knowledge in STEM fields enables citizens to make thoughtful decisions about important scientific and engineering programs (Ravitch 2013). Classrooms in the USA are becoming increasingly inclusive (Ernst et al. 2014). It is important for children of new immigrants to actively participate in STEM opportunities that have prospective impacts on the future development of their country. However, student disabilities or non-proficiency in language obstructs them from STEM learning and career success. Underrepresented and underserved students should be given equal educational opportunity as their peers (Spring 2011). Students with categorical disabilities and LEP may need specialized programming, and their teachers should be prepared to help these students have an equal chance of succeeding in STEM education classrooms and future careers.

Kennedy (1999) pointed out the importance of pedagogical content knowledge for science teaching. The significance of developing knowledge and strategies beyond subject content should be valued by STM teachers. Professional development that is closely aligned with practice helps teachers address student learning objectives and misconceptions (Penuel et al. 2007). For teachers to make substantial changes in their classroom practices, a considerable amount of professional development is needed (Wei et al. 2009). However, the results from this study indicate that STM teachers tend to engage in fewer professional development opportunities regarding students with categorical disabilities, as well as LEP, than the remainder of the teaching population. Even among the STM teachers indicating engagement in the categorical professional development opportunities, fewer hours of participation were reported.

Technology education teachers are more closely aligned with the broader teacher population than science educators and mathematics educators, although technology educators are the least likely to actually participate in LEP professional development. The naturally integrative nature of technology education paired with its absence of required accountability testing may have resulted in its close alignment with the broader educational community in that it possesses some notable intersections and similar professional requirements and needs. Through general observation, there are a multitude of professional development opportunities for STM educators. However, many of these tend to be initiative-based or content-specific. This current trend in professional development offerings could be a contributing factor in STM educators not being active participants in practice-centric opportunities. Wei et al. (2010) reported that national investments in teacher learning regarding teaching LEP and students with disabilities appear to trend toward focusing on ineffective short-term workshops. Teachers, especially science and mathematics educators, should be encouraged to participate in and be offered more opportunities of quality practice-oriented professional development. A limitation of the data collected is the inability to elaborate on the types of activities that teachers attended. Teachers evaluated the utility of all the professional development activities they have participated in targeting students with disabilities and LEP during the school year.

Table 8 Perceived utility of professional development regarding students with LEP (question 49c)

\begin{tabular}{|c|c|c|c|c|c|}
\hline Area & Not useful $n(\%)$ & Somewhat useful $n(\%)$ & Useful n (\%) & Very useful $n(\%)$ & Total \\
\hline Mathematics & $6730(9.61)$ & $30,860(44.10)$ & $23,740(33.93)$ & $8640(12.35)$ & 69,970 \\
\hline Science & $3330(6.28)$ & $22,460(42.37)$ & $19,820(37.38)$ & $7410(13.97)$ & 53,010 \\
\hline Technology & $910(9.45)$ & $3330(34.72)$ & $3190(33.26)$ & $2170(22.56)$ & 9600 \\
\hline Total STM & $10,960(8.27)$ & $56,650(42.73)$ & $46,750(35.26)$ & $18,210(13.74)$ & 132,570 \\
\hline All others & $40,360(5.22)$ & $236,630(30.60)$ & $336,870(43.56)$ & $159,490(20.62)$ & 773,350 \\
\hline Total & $51,320(5.67)$ & $293,280(32.37)$ & $383,620(42.35)$ & $177,700(19.62)$ & 905,920 \\
\hline
\end{tabular}

Weighed sample values are rounded to the nearest 10 per NCES protocol 


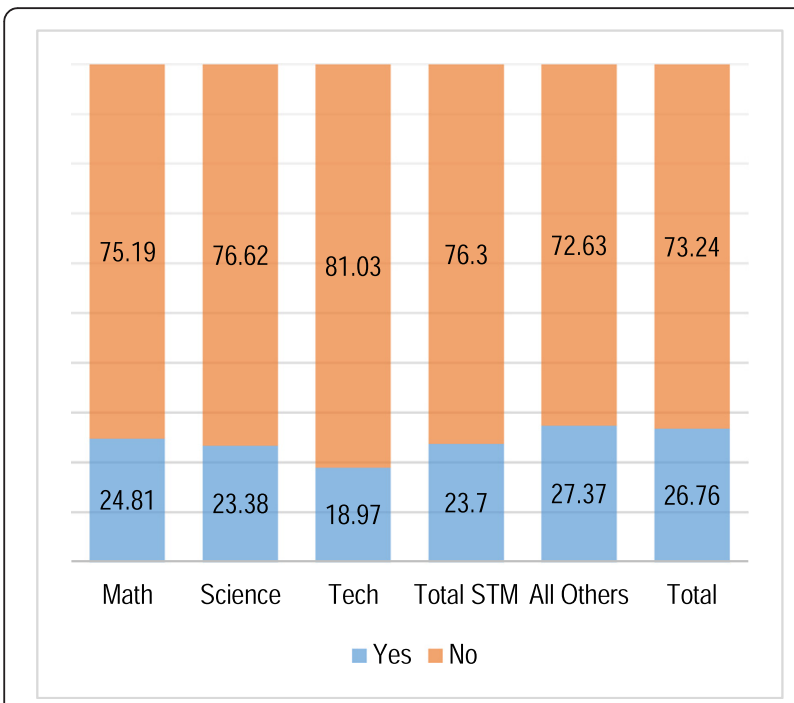

Fig. 6 Participation in professional development regarding students with LEP (question 49a)

Overall, STM teachers' perceived utility of the provided professional development experience was lower than that of the remainder of the teaching population. Most notably, science educators tend to find the professional development less useful when it is related to teaching students with categorical disabilities, while mathematics educators find it less useful in teaching students with LEP.

These descriptive results may raise further interest among STEM educators and researchers on the granular level of professional development experiences for STEM teachers. Given the intent of the current study, descriptive statistical procedures provided a general overview and useful estimated information on the target population.

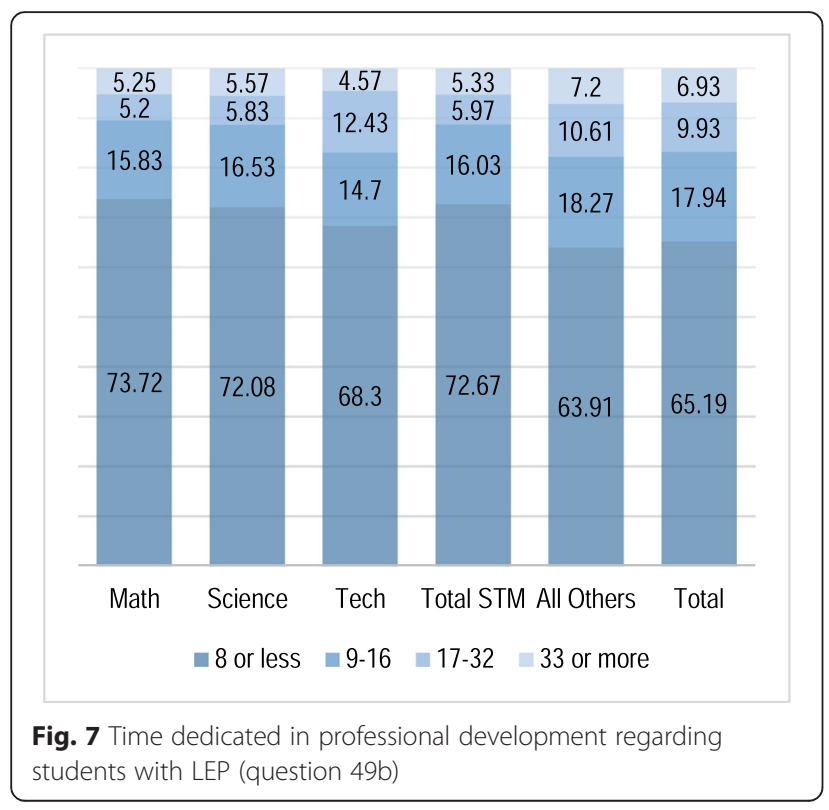

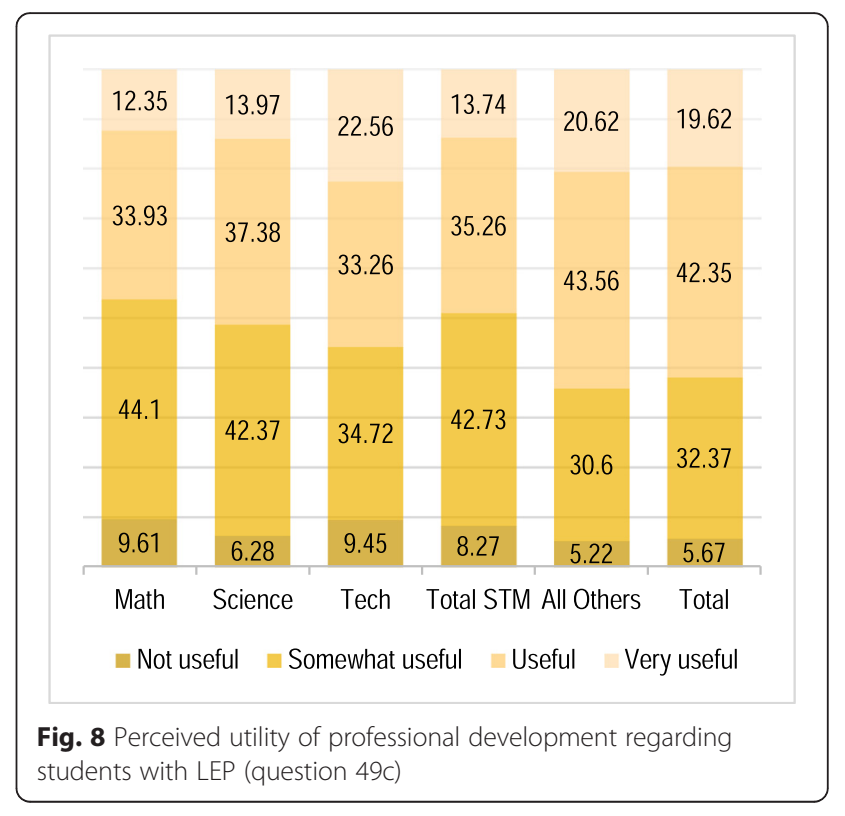

These findings stand to be further advanced through a separate qualitative study to explore the issues that STM teachers have found in their professional development experiences related to students with disabilities and those with LEP. However, the current dataset does not permit an analysis of the relationships between teachers' professional development and their actual teaching outcome. Another limitation of the study is that school level (elementary, middle, or high school) is not consistent across the USA. Therefore, grade level is not a viable separation within the closed dataset. Even so, SASS TQ offers potential for future research investigating connections and correlations across results that could provide more information on the topic and suggests areas of interest to enlighten future studies.

Alternative formats of professional development may be needed to improve teacher perceived utility. Aligned educational school goals would also help teachers build coherence between these professional development opportunities and their own teaching objectives (Lumpe et al. 2000). Furthermore, the concepts of universal design, as well as practical techniques such as the use of internet resources, multimedia demonstration methods, and teaching applications should be introduced to teachers, in accord with equipment and accessible resources. It is necessary for contemporary STEM education teachers to raise the awareness of the importance of pedagogical content knowledge and knowledge about learners. Sufficient and useful professional development programs, addressing the special needs of students with LEP and categorical disabilities, are necessary in order to adequately understand student needs and adapt classroom practices for diverse learner groups within the new integrated STEM learning context. 


\section{Competing interests}

The authors declare that they have no competing interests.

\section{Authors' contributions}

This article was a collaborative work of three authors. The primary author SL proposed the research idea, designed the study, wrote the bulk of the manuscript, prepared the charts and tables, and participated in all stages of development as well as being the primary person to respond to reviewer questions and complete manuscript revisions. JVE contributed to the conclusions, the literature review and development, and framing the research questions, editing, and answering reviewer questions. TOW contributed to IES data approval process, data acquisition, data analysis, methods and results, and editing and answering reviewer questions. The workload allocation was about 60,20 , and $20 \%$, respectively. All authors read and approved the final manuscript.

\section{Author details}

${ }^{1}$ Integrative STEM Education, School of Education, Virginia Tech, 366 Smyth Hall, Blacksburg, VA 24061, USA. ${ }^{2}$ Integrative STEM Education, School of Education, Virginia Tech, 115 War Memorial Hall, Blacksburg, VA 24061, USA. ${ }^{3}$ Special Education, School of Education, Virginia Tech, 314 War Memorial Hall, Blacksburg, VA 24061, USA.

Received: 28 May 2015 Accepted: 11 December 2015

Published online: 29 December 2015

\section{References}

Avalos, B. (2011). Teacher professional development in teaching and teacher education over ten years. Teaching and Teacher Education, 27(1), 10-20.

Burgstahler, S., \& Doe, T. (2004). Disability-related simulations: if, when, and how to use them in professional development. Review of Disability Studies: An International Journal, 1, 2. Retrieved from http://www.rds.hawaii.edu/ojs/ index.php/journal/article/download/385/1182

Crippen, K. J., \& Archambault, L. (2012). Scaffolded inquiry-based instruction with technology: a signature pedagogy for STEM education. Computers In The Schools, 29(1/2), 157-173. doi:10.1080/07380569.2012.658733.

Ernst, J. V., Li, S., \& Williams, T. O. (2014). Secondary engineering design graphics educator service load of students with identified categorical disabilities and limited English proficiency. Engineering Design Graphics Journal, 78, 1.

Gándara, P. (2006). Strengthening the academic pipeline leading to careers in math, science, and technology for Latino students. Journal of Hispanic Higher Education, 5(3), 222-237.

García, O. (2009). Emergent bilinguals and TESOL: what's in a name? TESOL Quarterly, 43(2), 322-326.

Goeke, J. L., \& Ciotoli, F. (2014). Inclusive STEM: making integrative curriculum accessible to all students. Children's Technology \& Engineering, 18(3), 18-22.

Hart, J. E., \& Lee, O. (2003). Teacher professional development to improve the science and literacy achievement of English language learners. Bilingua Research Journal, 27(3), 475-501.

Kennedy, M. (1999). Form and substance in mathematics and science professional development (NISE Brief No. 3[2]). Madison, WI: National Center for Improving Science Education.

Lee, O., Adamson, K., Maerten-Rivera, J., Lewis, S., Thornton, C., \& LeRoy, K. (2008). Teachers' perspectives on a professional development intervention to improve science instruction among English language learners. Journal of Science Teacher Education, 19, 41-67.

Lee, O., Deaktor, R., Enders, C., \& Lambert, J. (2008). Impact of a multiyear professional development intervention on science achievement of culturally and linguistically diverse elementary students. Journal of Research in Science Teaching, 45(6), 726-747.

Lee, O., Hart, J. E., Cuevas, P., \& Enders, C. (2004). Professional development in inquiry-based science for elementary teachers of diverse student groups. Journal of Research in Science Teaching, 41(10), 1021-1043.

Lumpe, A., Haney, J., \& Czerniak, C. (2000). Assessing teachers' beliefs about their science teaching context. Journal of Research in Science Teaching, 37, 275-292.

McCutchen, D., Abbott, R. D., Green, L. B., Beretvas, S. N., Cox, S., Potter, N. S., et al. (2002). Beginning literacy: links among teacher knowledge, teacher practice, and student learning. Journal of Learning Disabilities, 35, 69-86.

Nadelson, L. S., Seifer, A., Moll, A. J., \& Coats, B. (2012). I-STEM summer institute: an integrated approach to teacher professional development in STEM. Journal of STEM Education, 13(2), 69-83.
NCES (n.d.). Sample selection. Retrieved from https://nces.ed.gov/surveys/sass/ overview.asp

Newman, L., Wagner, M., Knokey, A. M., Marder, C., Nagle, K., Shaver, D., et al. (2011). The post-high school outcomes of young adults with disabilities up to 8 years after high school: a report from the National Longitudinal Transition Study-2 (NLTS2) (NCSER 2011-3005). Menlo Park, CA: SRI International.

Nimisha, P., Suzanne, F., Yoko, M., \& Brian, B. (2012). Including curriculum focus in mathematics professional development for middle-school mathematics teachers. School Science \& Mathematics, 112(5), 300-309.

Penuel, W. R., Fishman, B. J., Yamaguchi, R., \& Gallagher, L. P. (2007). What makes professional development effective? Strategies that foster curriculum implementation. American Educational Research Journal, 44(4), 921-958. doi: 10.3102/0002831207308221.

Podhajski, B., Mather, N., Nathan, J., \& Sammons, J. (2009). Professional development in scientifically based reading instruction: teacher knowledge and reading outcomes. Journal of Learning Disabilities, 42(5), 403-417.

President's Council of Advisors on Science and Technology (US) (2010). Prepare and inspire: K-12 education in science, technology, engineering, and math (STEM) for America's future: executive report. Executive Office of the President, President's Council of Advisors on Science and Technology.

Ravitch, D. (2013). Reign of error: the hoax of the privatization movement and the danger to America's public schools. New York: Random House.

Richards, E., \& Terkanian, D. (2013). Occupational employment projections to 2022. Monthly Labor Review, Retrieved from http://www.bls.gov/opub/mlr/2013/ article/pdf/occupational-employment-projections-to-2022.pdf.

Rivero, A., Azcarate, P., Porlan, R., Martin del Pozo, R., \& Harres, J. (2011). The progression of prospective primary teacher conceptions of the methodology of teaching. Research in Science Education, 41(5), 739-769.

Rule, A. C., Stefanich, G. P., \& Boody, R. M. (2011). The impact of a working conference focused on supporting students with disabilities in science, technology, engineering, and mathematics (STEM). Journal of Postsecondary Education \& Disability, 24(4), 351-367.

Schumm, J. S., \& Vaughn, S. (1995). Meaningful professional development in accommodating students with disabilities: lessons learned. Remedial and Special, 16(6), 344-353.

Sotomayer, K. (2013). Teaching STEM to English-language learners. Principal, 92(3), 40-41.

Spring, J. (2011). American education. New York, NY: McGraw-Hill.

Tourkin, S, Thomas, T, Swaim, N, Cox, S, Parmer, R, Jackson, B, Cole, C, Zhang, B (2010). Documentation for the 2007-08 Schools and Staffing Survey (NCES 2010-332). U.S. Department of Education. Washington, DC: National Center for Education Statistics. Retrieved from http://nces.ed.gov/pubsearch

Wei, R. C., Darling-Hammond, L., \& Adamson, F. (2010). Professional development in the United States: trends and challenges. Dallas, TX: National Staff Development Council.

Wei, R. C., Darling-Hammond, L., Andree, A., Richardson, N., \& Orphanos, S. (2009). Professional learning in the learning profession: a status report on teacher development in the United States and abroad. Dallas, TX: National Staff Development Council.

Yu, K., Lin, K., Han, F., \& Hsu, I. (2012). A model of junior high school students' attitudes toward technology. International Journal of Technology and Design Education, 22(4), 423-436.

Zehr, M. (2010). New ELL chief stresses science, teacher preparation. Education Week, 30(12), 8-11.

\section{Submit your manuscript to a SpringerOpen ${ }^{\circ}$ journal and benefit from:}

- Convenient online submission

- Rigorous peer review

- Immediate publication on acceptance

- Open access: articles freely available online

- High visibility within the field

- Retaining the copyright to your article

Submit your next manuscript at springeropen.com 